\title{
A GEOGRAFIA DO COTIDIANO E A APRENDIZAGEM SIGNIFICATIVA NOS ANOS INICIAIS
}

The daily geography and the meaningful learning in the early years

La geografía del cotidiano y el aprendizaje significativo en los años iniciales

Crislane da Silva Oliveira ${ }^{1}$ http://orcid.org/0000-0002-2951-7818

Andrecksa Viana Oliveira Sampaio ${ }^{2}$ http://orcid.org/0000-0002-7826-0908

\footnotetext{
${ }^{1}$ Especialista em Analise do Espaço Geográfico pela Universidade Estadual do Sudoete da Bahia - UESB, Brasil Mestranda do Programa de Pós-Graduação em Geografia PPGEO -UESB, email - crisolveirageo@gmail.com

${ }^{2}$ Professor(a) Adjunto do Departamento de Gografia da Universidade Estadual do Sudoete da Bahia - UESB, Brasil, email viladea@yahoo.com.br
}

\section{Resumo}

A aprendizagem é um processo inerente ao aluno que deve assumir a função de questionar, dialogar e aprender. Com os avanços tecnológicos, a sociedade tem passado por transformações que resultam em práticas pedagógicas e construção de novos saberes. Na escola, a Geografia traz uma leitura de mundo aos educandos privilegiando a relação sociedade e natureza. Este artigo tem por objetivo compreender como acontece a aprendizagem significativa nos anos iniciais a partir do ensino de Geografia e baseiase nas ideias de Straforini (2001), Ponthuscka (2007), Freire (1996), dentre outros. A aprendizagem é considerada significativa quando se relaciona com os outros conceitos e suposições relevantes, disponíveis na mente do estudante, no qual servem de suportes para que sejam introduzidas novas aprendizagens.

Palavras-chave: Aprendizagem Significativa. Ensino de Geografia. Geografia do cotidiano.

\begin{abstract}
The act of learning is an inherent process for the student, who must take on the role of questioning, talking and learning. With the technological advances, the society has undergone transformations that results in pedagogical practices and construction of a further knowledge. In school, Geography brings a measure of the world to the learners privileging the relationship between society and nature. This article aims to understand how the meaningful learning in the initial years occurs from the teaching of Geography and is based on the ideas of Straforini (2001), Ponthuscka (2007), Freire (1996), among others. The act of learning is considered significant when it's related to the other relevant concepts and assumptions available in the student's mind, in which they serve as a basis for introducing the new learning.
\end{abstract}

Keywords: Meaningful Learning. Teaching of Geography. Geography of daily life. 


\begin{abstract}
Resumen
La aprendizaje es un proceso inherente al alumno, que debe asumir la función de cuestionar, dialogar y aprender. Con los avances tecnológicos, la sociedad ha pasado por transformaciones que resultan en prácticas pedagógicas y construcción de nuevos saberes. En la escuela, la geografía trae una lectura mundo a los educandos privilegiando la relacción entre sociedad y la naturaleza. Este artículo tiene como objectivo comprender cuán significativo es el aprendizaje en los años iniciales a partir de la enseñanza de la Geografía y se basa en las ideas de Straforini (2001), Ponthuscka (2007), Freire (1996), entre otros. El aprendizaje es considerado significativo cuando se relaciona con los otros conceptos y suposiciones relevantes, disponibles en la mente del estudiante, en que sirven de soportes para que se introduzcan nuevos aprendizajes.
\end{abstract}

Palabras clave: Aprendizaje Significativo. Enseñanza de Geografía. Geografía del cotidiano.

\title{
Introdução
}

A aprendizagem significativa, definida por Ausubel (1982) como aprendizagem por descoberta/aprendizagem receptiva está ligada ao aprendizado do aluno, que pode ocorrer tanto pela descoberta de novos conteúdos, quanto pela maneira como ele assimila e recebe os conteúdos.

Dessa forma, a preocupação inicial gira em torno de como o aluno absorve os conteúdos necessários para o seu aprendizado: quanto mais próximo da aprendizagem por descoberta, mais os conteúdos serão recebidos de forma inacabada, assim, antes de assimilar o conteúdo, o aluno deve descobri-los ou defini-los. Caso contrário, quanto mais se aproxima da aprendizagem receptiva, esses conteúdos serão apreendidos pelos alunos na forma final, num processo encerrado (PELIZZARI et al., 2002).

Esse artigo apresenta a discussão teórica sobre Ensino de Geografia, aprendizagem significativa e Geografia do cotidiano e norteia a pesquisa em andamento desenvolvida na linha de Ensino de Geografia do Curso de Especialização em Análise do Espaço Geográfico com o objetivo de compreender como acontece a aprendizagem significativa dos anos iniciais, no ensino de Geografia. 


\section{A Aprendizagem Significativa e o Ensino de Geografia}

O método da aprendizagem siginificativa proposta por Ausubel (1982) traz para o educando grandes vantagens, seja contribuir para o enriquecimento do conhecimento que o aluno porta, seja para adquirir novos conhecimentos. O autor destaca a importância da aprendizagem memorística, como sendo um processo que interfere no aprendizado, por um lado pode ser delimitado pela aprendizagem significativa, por outro um processo mecânico ou repetitivo. Nessa perspectiva, Pelizzari et al. (2002) com base na teoria de Ausubel apresenta três benefícios a partir da aprendizagem memorística:

Em primeiro lugar, o conhecimento que se adquire de maneira significativa é retido e lembrado por mais tempo. Em segundo, aumenta a capacidade de aprender outros conteúdos, de uma maneira mais fácil, mesmo se a informação original for esquecida. E, em terceiro, uma vez esquecida, facilita a aprendizagem seguinte - a reaprendizagem", para dizer de outra maneira (PELIZZARI et al, 2002, p. 39 - 40).

Os processos de ensino e aprendizagem exigem uma relação de diálogo entre professor e aluno, sendo o professor responsável pelo planejamento e desenvolvimento das atividades que possibilitem a construção do conhecimento do aluno. A aprendizagem pode ser entendida como um processo inerente ao aluno e este deve assumir a função de querer, pensar, questionar, dialogar, aprender. No entanto, o professor necessita ter clareza e conhecimentos tanto dos processos pedagógicos, como dos conteúdos a serem trabalhados.

Nessa direção, surge a necessidade de compreender melhor as representações sociais presentes no cotidiano dos alunos e que se tornam especialmente significativas, pois criam possibilidades de analisar os vários aspectos da educação. Mendes (2011) assinala a importância dos coletivos sociais, no constructo social dessa categoria, ao afirmar:

[...] o nosso cotidiano é atravessado por uma multiplicidade de ações e vozes que instituem representações sociais partilhadas por determinados grupos, assim, é inegável que as representações sociais são elaboradas no âmbito dos fenômenos comunicacionais. A comunicação social seria, portanto, responsável pelo modo como se forjam essas representações (MENDES, 2011, p.10).

Desde as épocas mais remotas, as sociedades se expressam através dos espaços vividos por meio de representações, que estiveram sempre impregnadas aos valores provenientes da própria cultura. Para Mendes (2011), as representações sociais podem ser entendidas como fenômenos socialmente construídos, de forma que não podem ser vistas fora de uma perspectiva de interpenetração recíproca, formando uma complexa rede de relações 
que se manifestam nas atitudes, comportamentos e apreensões individuais e coletivas. $\mathrm{O}$ termo representação está interligado a outras categorias como: cultura, símbolos, crenças, valores, visão de mundo, entre outras.

$\mathrm{O}$ ensino tem por objetivo garantir a aprendizagem ativa dos alunos, levando em conta os seus saberes, experiências e significados. A Geografia, seja como ciência ou como matéria de ensino, desenvolveu conceitos e categorias que são imprescindíveis para o estudo dos fenômenos a partir do ponto de vista geográfico. Assim, Corrêa apresenta os conceitos fundamentais para o estudo da Geografia:

Como ciência social a geografia tem como objeto de estudo a sociedade que, no entanto, é objetivada via cinco conceitos-chaves que guardam entre si forte grau de parentesco, pois todos se referem à ação humana modelando a superfície terrestre: paisagem, região, espaço, lugar e território (CORRÊA, 2013, p. 16).

A Geografia tem papel fundamental na sociedade, pois possibilita ao estudante uma compreensão mais aprofundada de sua realidade, bem como o significado de sua espacialidade. Logo, a Geografia Escolar tem como função alfabetizadora, inserir o seu objeto de estudo - o espaço - numa perspectiva interdisciplinar, de forma que dialogue com as outras áreas do conhecimento, sendo possível realizar uma leitura de mundo.

Ensinar Geografia consiste na compreensão do espaço, sem negar a sua temporalidade. Quando se ministra Geografia, o professor desenvolve no aluno diferentes possibilidades de conhecimentos, fazendo-o ter uma leitura concisa e diversificada do lugar onde se vive e também do mundo que o cerca. Selbach corrobora essa ideia quando enfatiza:

Ensina-se Geografia para que os alunos possam construir e desenvolver uma compreensão do espaço e do tempo, fazer uma leitura coerente do mundo e dos intercâmbios que o sustentam, apropriando-se de conhecimentos específicos e usando-os como verdadeira ferramenta para seu crescimento pessoal e para suas relações com os outros (SELBACH, 2010, p.37).

Nesse viés é importante ressaltar que existem várias discussões acerca da ciência geográfica e do conhecimento que a perpassa. O lecionar e o aprender implicam numa ação pedagógica na qual professor e aluno assumem um compromisso perante o processo de ensino e aprendizagem.

Nos anos iniciais, a Geografia era organizada dentro dos "Estudos Sociais" que representou uma aproximação entre três ciências: a Geografia, a História e a Sociologia, e 
acabou por gerar uma desordem tanto teórica quanto metodológica, pois cada ciência tem a sua particularidade.

Os signos (elementos conceituais) trabalhados nos anos iniciais através dos estudos sociais por alguns momentos foram descontextualizados, frente ao mundo dos alunos. Vale ressaltar que os significados são acadêmicos e que por muitas vezes são incompreensíveis pelos próprios docentes, o que provoca a falta de significado ao educando. Ainda nos dias atuais há pouca aproximação da escola com a vida e o cotidiano dos estudantes (CASTROGIOVANNI, 2012).

A todo instante a sociedade passa por constantes transformações e consequentemente a ciência precisa se reinventar para acompanhar tais mudanças, assim o espaço e o tempo ganham novas leituras. Dessa forma, se faz necessário, nos primeiros anos da escolarização, um trabalho voltado para a valorização do tempo e do espaço.

Alguns autores como Callai (2005) e Catrogiovanni (2012), veem na Geografia dos anos iniciais a possibilidade de auxiliar na formação de cidadãos críticos. Straforoni (2001), afirma que por muito tempo o ensino de Geografia nos anos iniciais vem apresentando ao aluno uma visão distorcida do conceito de espaço geográfico. $\mathrm{O}$ autor ainda ressalta a importância da teoria construtivista proposta por Piaget. A partir desta, a realidade do aluno passa a ser introduzida na escola e a realidade passa a ser considerada como ponto de partida (STRAFORINI, 2001). Considerando a realidade do aluno, qual seria o ponto de partida para se trabalhar a Geografia nos anos iniciais?

No decorrer do tempo foram desenvolvidas novas maneiras de trabalhar os conteúdos geográficos atreladas as diversas metodologias como: discussões de textos, apresentações de trabalhos, aulas de campo, exposição e vídeos, slides, dentre outras atividades que destacam a importância da Geografia para a vida do ser humano, acarretando numa melhoria do seu ensino.

Há uma busca constante por parte dos professores em apresentar uma Geografia que não é somente baseada em dados isolados e, que nada contribui para a compreensão do mundo em se que se vive. A preocupação dessa ciência está relacionada às questões de espacialidade. Apesar de todos os recursos atuais, a ideia de que a Geografia é uma ciência descritiva sobre a Terra ressurge sistematicamente na sociedade, pois a escola não ensina o que é a Geografia (GOULART, 2012).

Para Castellar (2005), estudar a Geografia parte do lugar e da relação entre os lugares, como também da leitura dos fenômenos em diferentes escalas, para que assim o aluno possa 
conhecer a sua realidade, através da leitura do espaço vivido. A autora afirma que através do estudo da realidade a Geografia ganha significado e ressalta:

Deve começar a estabelecer relações entre os lugares, a ler os fenômenos em diferentes escalas, mobilizando o raciocínio e educando o olhar para que possa fazer a leitura do espaço vivido. O saber agir sobre o lugar de vivência é importante para que o aluno conheça a realidade e possa comparar diferentes situações, dando significado ao discurso geográfico - isso seria a concretização da educação geográfica, do mesmo modo que ocorre com a Matemática, a Física, ou outras áreas do conhecimento escolar (CASTELLAR, 2005, p. 213)

Nas últimas décadas do século $\mathrm{XX}$, o ensino de Geografia foi alvo de diversas discussões, sobretudo na dificuldade de se romper com a Geografia tradicional e de repensar o seu papel na sociedade. Nesse sentido, Cavalcanti afirma:

Particularmente, a Geografia escolar tem procurado pensar o seu papel nessa sociedade em mudança, indicando novos conteúdos, reafirmando outros, reatualizando alguns outros, questionando métodos convencionais, postulando novos métodos (CAVALCANTI, 2002, p.11).

Essas questões remetem às especificidades de uma nova concepção de ensino de Geografia, que leve o aluno a compreender o espaço geográfico e a sua transformação ao longo do tempo, numa perspectiva crítica, em que os conteúdos ensinados precisam ter relação com as vivências e o cotidiano, assim a aprendizagem passa a fazer sentido. Desse modo, o objetivo primordial da Geografia lecionada nas salas de aulas é desenvolver no aluno a consciência espacial da realidade que eles vivenciam. Cavalcanti ainda ressalta:

O trabalho de educação geográfica na escola consiste em levar as pessoas em geral, os cidadãos, a uma consciência da espacialidade das coisas, dos fenômenos que elas vivenciam, diretamente ou não, como parte da história social (CAVALCANTI, 2002, p.12 -13).

Surge então a necessidade de se romper com a Geografia Tradicional e para isso é necessário que se crie concepções teórico-metodológicas apropriadas que permita ao sujeito o reconhecimento do saber do outro, desenvolvendo neste a capacidade de fazer a leitura de mundo, reconhecendo a sua dinâmica e superando aquilo que era visto como verdade absoluta (CALLAI, 2005). 
Todavia, alguns professores ainda apresentam aos alunos uma Geografia pautada na quantidade de informações fora do contexto da realidade dos alunos ou dos acontecimentos do mundo. Goulart (2012), explica:

Isso ocorre porque ainda continuamos procurando apoiar nosso trabalho naquilo que chamamos de conteúdo. Essas listagens, com títulos nem sempre entendidos pelos próprios professores, seguem uma ordenação que dificulta a conexão e as possibilidades de trabalhar com a totalidade, ainda que na geografia as redes possam ser facilmente estabelecidas, se o professor conhece as temáticas sobre as quais está ensinado (GOULART, 2012, p. 10$11)$.

Pontuschka et al. (2007) ressalta que muitas das linguagens e tecnologias atuais, pouco penetram as salas de aula. Para a autora, essa questão deve ser trabalhada com urgência, a fim de que os professores possam utilizá-las de forma crítica em suas práticas na sala de aula e apresenta a cartografia, não simplesmente como uma disciplina escolar que ajuda no desenvolvimento da noção espacial, mas como representação e linguagem, de tal modo, que permita ao aluno fazer a leitura do espaço tanto na escala global como na escala mundial. E afirma:

Na formação de professores e alunos, é essencial o domínio da leitura do espaço por meio de observação espontânea e dirigida, das entrevistas, da produção de registros e da pesquisa em variadas fontes, nas realidades locais concretas do bairro ou de cidades. Tais procedimentos constituem pontos de partida e chegada, nos quais se constroem os parâmetros reais para a compreensão de espaços locais e de regiões bem mais distantes (PONTUSCHKA et al., 2007, p.39).

Nessa direção, para que se concretize de fato o processo da aprendizagem geográfica é preciso que as temáticas apresentem sentido aos educandos. As atividades por sua vez devem ser atraentes e lúdicas despertando no educando a curiosidade por conhecer os diferentes contextos. Aprender Geografia, bem como as outras áreas do conhecimento "significa estabelecer um diálogo entre o conhecimento, isto é, pensar sobre aquilo que está sendo produzido, questionando as diferentes etapas e estabelecendo conexões com diferentes conceitos já construídos" (GOULART, 2012, p. 12).

O conhecimento cotidiano dá suporte aos conceitos formulados, com base em novas informações que podem estar ligadas com a experiência educativa, com a educação formal, ou até mesmo com o senso comum. 
De tal forma para que se possa compreender os processos de construção e transformação do espaço geográfico na perspectiva do ensino significativo de Geografia é necessário analisar o lugar como experiência imediata do espaço vivido e apropriado pelos sujeitos sociais, tal como aponta Carlos:

[...] o lugar guarda em si e não fora dele o seu significado e as dimensões do movimento da vida, possível de ser apreendido pela memória, através dos sentidos e do corpo. O lugar se produz na articulação contraditória entre o mundial que se anuncia e a especificidade histórica do particular. Deste modo o lugar se apresentaria como ponto de articulação entre a mundialidade em constituição e o local enquanto especificidade concreta, enquanto momento. (CARLOS, 1996, p.14, grifo do autor).

O homem admira a paisagem e os lugares distantes, entretanto não conhece o que existe e o que acontece no lugar em que vive. Logo, ao estudar o espaço geográfico, é necessária a delimitação do mesmo, pois o espaço é imenso e tal delimitação ocorre em vários níveis: o local, o regional, o nacional e o global, tendo como ponto de partida o local.

Estudar o lugar é fundamental, pois ao mesmo tempo que o mundo é global, as relações sociais se estabelecem em lugares específicos. É necessário que se pense dialeticamente a relação global e local, que fragmentam o espaço. A compreensão do lugar permite ao sujeito conhecer a sua história, apreendendo as coisas que ali acontecem (CALLAI, 2012).

Sobre a leitura do espaço, Callai (2012) aponta que umas das formas de ler o espaço se dá através do mapa. O mapa é um instrumento que auxilia na compreensão de determinado lugar. Para saber ler e entender um mapa é necessário que ocorra a alfabetização cartográfica, desenhar trajetos, percursos, plantas da sala de aula, pode ser o começo do aprender a fazer mapas, partindo da representação de um lugar conhecido, do dia a dia dos educandos.

Pode-se dizer que dentro do processo de globalização que tem por tendência homogeneizar os espaços, o lugar assume um papel importante, ao mesmo tempo em que a globalização cria uma lógica que fragmenta o espaço. Contudo, os grupos sociais que ali habitam podem reagir de diferentes formas a esse processo, pois cada lugar tem suas marcas no qual permite ao sujeito construir a sua identidade. "O que acontece na vida de uma sociedade acaba criando marcas no espaço, ou outra, a sociedade deixa marcas no espaço suas marcas" (CALLAI, 2012, p. 93).

Ao refletir sobre o lugar e sua articulação entre os processos da produção do espaço global e as singularidades do local, observa-se ainda que "[...] o lugar guarda uma dimensão prático-sensível, real e concreta que a análise, aos poucos, vai revelando" (CARLOS, 2007, 
p.15). Considerar a relevância da compreensão do lugar no aprendizado de Geografia permite também refletir sobre os múltiplos significados da docência. Nesse contexto, Freire, ao ponderar sobre essa questão, afirma:

Ao pensar sobre o dever que tenho, como professor, de respeitar a dignidade do educando, sua autonomia, sua identidade em processo, devo pensar também, como já salientei, em como ter uma prática educativa em que aquele respeito, que sei dever ter ao educando se realize em lugar de ser negado. Isto exige de mim uma reflexão crítica permanente sobre minha prática através da qual vou fazendo a avaliação do meu próprio fazer com os educandos. O ideal é que, cedo ou tarde, se invente uma forma pela qual os educandos possam participar da avaliação. É que o trabalho do professor é o trabalho do professor com os alunos e não do professor com ele mesmo (FREIRE, 1996, p.25).

As reflexões de Freire corroboram as discussões em torno da dimensão crítica da arte de educar, considerando a aprendizagem significativa. Dessa forma, para que ocorra a aprendizagem significativa dos conteúdos trabalhados em sala, compete ao professor saber identificar as bases de conhecimentos e informações, para assim estabelecer um paralelo entre senso comum e conceitos, instituindo oportunidades de novas aprendizagens. Freitas e Salvi (2007) trazem apontamentos sobre a aprendizagem significativa ao afirmar:

Para ser significativa a aprendizagem tem que estabelecer uma interação entre a nova informação e um elemento cognitivo da estrutura metal do aprendiz, não um elemento aleatório, mas sim aquele elemento dê possibilidades de desenvolvimento e modificações (FREIRE e SALVI, 2007, p. 02).

Uma informação é considerada significativa quando se relaciona com os outros conceitos, suposições dotadas de relevância, cabíveis no intelecto do estudante, ou seja, disponíveis na mente do aprendiz, no qual servem de suportes para que possam ser introduzidas novas aprendizagens.

Para Pelizzari et al (2002), algumas condições devem ser consideradas para que haja a aprendizagem significativa. Na primeira o estudante deve estar disposto a aprender, não simplesmente memorizar o conteúdo, pois assim a aprendizagem será mecânica. Na segunda o conteúdo escolar deve ter sentido logico e ser psicologicamente significativo, o lógico partindo do conteúdo a ser ministrado em sala de aula e, psicológico partindo da experiência que cada sujeito tem, no momento em que o aprendiz filtra o conteúdo, este pode apresentar ou não um significado para si. 
Nesse sentido, as atividades lúdicas são fundamentais para o processo de ensino e aprendizagem, sobretudo nos anos iniciais, pois se tornam instrumentos de aprendizagem que contribui para a aquisição do conhecimento. Para Freitas e Salvi (2007), o lúdico deve ser uma ferramenta utilizada como estimulo na construção do conhecimento, cuja finalidade alcança objetivos institucionais. Assim a autoras sinalizam:

O lúdico é uma estratégia insubstituível para ser usada como estimulo na construção do conhecimento humano e na progressão das diferentes habilidades operatórias, além disso, é uma importante ferramenta de progresso pessoal e de alcance de objetivos institucionais (FREIRE e SALVI, 2007, p. 04)

Acredita-se que ao utilizar a ludicidade como recurso aliado à educação, o educando consegue assimilar de forma ativa os seus esquemas mentais com a realidade concreta que o cerca. Sendo assim, é correto se afirmar que a realidade pode ser construída e assimilada a partir de atividades lúdicas. Lembrando que o lúdico não está somente ligado a jogos e brincadeiras, mas a dinâmica de grupo, recorte e colagem, música, vídeos, atividades computadorizadas, dentre tantas outras.

Nessa perspectiva, a ludicidade como ferramenta para o processo de ensino e aprendizagem somente será válida quanto apresentar um caráter desafiador, despertando e estimulando o educando à construção do conhecimento, possibilitando a compreensão e intervenção do indivíduo nos fenômenos sociais e culturais, ao final a ludicidade deve atingir o objetivo proposto no planejamento do professor.

Através das aulas de Geografia é possível despertar no aluno o interesse em conhecer o mundo e de se reconhecer como cidadão que atua na construção do espaço. Conforme Straforini (2002) “o problema não está em ensinar Geografia a partir da realidade, mas o sentido que se dá a essa realidade".

Cabe ao docente pesquisar e trazer para a sala de aula diferentes propostas pedagógicas. O conhecimento adquirido pelo mesmo tem a necessidade de ser socializado como também estar acessível a todos. Entretanto, tal conhecimento precisa ser significativo de forma que possibilite ao aluno estabelecer ligações com algo que aprendeu com a realidade vivida (FREITAS e SALVI, 2007). 


\section{Considerações finais}

É importante refletir sobre a construção de conhecimentos geográficos, na escola, no qual traz a importância da Geografia para a vida dos alunos. A ciência geográfica, como disciplina escolar, contribui para que alunos e professores enriqueçam suas representações sociais e seu conhecimento sobre as múltiplas dimensões da realidade social, natural e histórica.

Portanto, o ensino de Geografia dos anos iniciais pode contribuir de forma significativa para o aprendizado do aluno, uma vez que esse sujeito a partir da leitura de mundo reconheça o lugar como seu espaço vivido, além de outros lugares, que estão próximos ou não da sua realidade.

\section{Referências}

CALLAI, Helena Copetti. Aprendendo a ler o mundo: a Geografia nos anos iniciais do ensino fundamental. Cad. Cedes, Campinas, vol. 25, n. 66, p. 227-247, maio/ago. 2005. Disponível em http://www.cedes.unicamp.br Acessado em: 11/08/2017

CASTELLAR, Sonia Maria Vanzella. Educação geográfica: a psicogenética e o conhecimento escolar. Cad. Cedes, Campinas, vol. 25, n. 66, p. 209-225, maio/ago. 2005. Disponível em <http://www.cedes.unicamp.br> Acessado em: 11/08/2017

CASTROGIOVANNI, Antonio Carlos (org.), CALLAI, Helena Copetti, KAERCHER, Nestor André. Ensino de Geografia: práticas e textualizações no cotidiano. 10. ed. - Porto Alegre: Mediação, 2012.

CAVALCANTI, Lana de Souza. Formação de Professores: Concepções e Práticas em Geografia. Goiânia: Editora Vieira, 2006.

CORRÊA, Roberto Lobato. Espaço: um conceito-chave da geografia. In: CASTRO, Iná Elias, GOMES, Paulo César da Costa, CORRÊA, Roberto Lobato (orgs.) Geografia: Conceitos e Temas. $5^{\text {a }}$ edição. Bertrand: Rio de Janeiro, 2003.

FREIRE, P. Pedagogia da Autonomia: saberes necessários a prática educativa. $25^{\mathrm{a}}$ Ed. São Paulo: Paz e Terra, 1996.

FREITAS, Eliane Sermidi; SALVI, Rosana Figueiredo. A ludicidade e a aprendizagem significativa voltada para o ensino de Geografia. Londrina, Universidade Estadual de Londrina, 2007.

GOULART, Beatriz Ligia. O que afinal um professor dos anos iniciais precisa saber para ensinar Geografia? Percursos, Florianópolis, v. 13, n. 02, p. 08 - 19, jul./dez. 2012. Disponível em <http://www.revistas.udesc.br/index.php/percursos/article/view/2763> Acessado em: 25/08/2017. 
MENDES, G. F. Memórias, discursos e representações sociais: um olhar para os 25 anos do Curso de Geografia da UESB. Vitória da Conquista: Edições UESB, 2011.

PELIZZARI, Adriana; KRIEGL, Maria de Lurdes; BARON, Márcia Pirih; FINCK, Nelcy Teresinha Lubi; DOROCINSKI. Teoria da Aprendizagem Significativa segundo Asubel. Rev. PEC, Curitiba, v.2, n.1, p.37-42, jul. 2001-jul. 2002.

PONTUSCHKA, Nídia Nacib (et al.). Para ensinar e aprender Geografia. São Paulo: Cortez, 2007.

SELBACH, S. Geografia e Didática. Petrópolis, RJ: Vozes, 2010.

STRAFORINI, Rafael. A totalidade mundo nas primeiras séries do ensino fundamental: um desafio a ser enfrentado. Terra Livre, São Paulo, v.1, n.18, p. 95-114, jan/jun. 2002.

Recebido em: 12/01/2018

Aceito para publicação em: 30/04/2018 